\title{
An Analysis of Traveler's Evaluation Frame Toward Public Transport Focusing on Dynamic Nature of Reference Point
}

\author{
Sarif $^{\#}$, Shinya Kurauchi ${ }^{*}$, Toshio Yoshii \\ ${ }^{\#}$ Graduate School of Science and Engineering, Ehime University, 3, Bunkyo-cho, Matsuyama, 790-8577, Japan \\ ${ }^{\#}$ Department of Civil Engineering, State Polytechnic of Ujung Pandang, 90245, Indonesia \\ E-mail: sarifpnup09@gmail.com
}

*Department of Civil and Environmental Engineering, Ehime University, 3, Bunkyo-cho, Matsuyama, 790-8577, Japan

E-mail:kurauchi@cee.ehime-u.ac.jp; yoshii@cee.ehime-u.ac.jp

\begin{abstract}
The internal reference point of traveler's decision-making is dynamic in nature. Public transport ridership considers a decision based on the utility value of gains and losses which can be modeled by using mental accounting theory. The objective of this research is to investigate the dynamic of internal reference points for public transport ridership after implementing transport policies. It describes the decision of travelers' behavior when facing the dynamic value of the utility, whether it is increasing, decreases or stable. In this study, a traveler's behavior model based on mental accounting theory was developed. The result showed that the public transport ridership's are more likely to change their reference point when realizing gains than losses for transport policies. Furthermore, the way of public transport ridership combines the decrease and increase of the utility value showed that travelers tend to consider which gains and losses occurred simultaneously. Therefore, the integration outcome is more desirable than segregation outcomes, and revealed that mental accounting theory plays a major role in public transport ridership. This survey was conducted for the short-term distance trip, particularly in shopping trip from the residential area (origin) to Community Business District (destination) in Matsuyama city, Japan.
\end{abstract}

Keywords - travel behavior analysis; internal reference point; mental accounting theory; travel mode choice; discrete choice analysis.

\section{INTRODUCTION}

A traveler's decision-making is constantly confronted with the option to use a private car or public transport to reach the destination. All transport users want to achieve the maximum utility by using alternative transport modes. The maximum utility that derived from the neoclassical economics is commonly used in the transport planning and policy system. It might be argued that in the main perception of travelers: rational behavior, consistent and efficient choices are assumed to obtain the maximum of their economic utility [1]. Their perception of uncertainty in terms of travel time, travel cost, and satisfaction makes them underestimate and overestimate, whether they are going for traveling in gains or loss area. Improving the public transport mode service can influence the intention of public transport ridership use public transport alternatives such as buses, light rail transit and the underground train [2]. Transport Demand Management (TDM) is widely adopted in the transport field in many cities over the world. It consists of several policies and strategies including expert advisory system that can be used to support transportation system [3]. Prospect theory (PT) has proposed a set of common assumptions that offer an alternative account of individual decision making under risk [4]. In 1985, a similar descriptive alternative to the deterministic economic theory of consumer choice was studied by Thaler. The study found a new concept in three distinct areas: coding gains and losses, evaluating purchases (transaction utility), and budgetary rules [5]. Prospect theory is a descriptive theory based on finding from cognitive psychology [6], and psychology in transport science is widely known as travel behavior research. The psychology of traveler is how they reach the maximum utility when performing traveling. Prospect theory has been widely applied in many studies and particularly applied in travel choice behavior. Prospect is based on observation of people's stated choices among risky alternatives [7]. The application of prospect theory is expected to provide a model approach for modeling travelers decision-making based on the internal reference point. The reference point in commuter departure time choice determines how an outcome may be viewed. In departure time choice research, the commuter might have more than 
one area when the outcome evaluated of a decision. One area for gains, another area for losses [8]. The decision-making process of passenger is calculated in cumulative prospect theory approach, the traveler is more interested in a minimum waiting time [9]. In order to identify the analysis of travel choices under risk and uncertainty, descriptive approach can be better addressed than normative approach. The travelers usually behave irrationally in response to risk and uncertainty as well as in predicting the normative model the traveler choice generally violate [10]. Modeling travel choice behavior can be well explained using prospect theory and cumulative prospect theory. When commuter faced with the gains area, they tend to risk aversion. When faced with the losses area, the commuter is greater degree of risk seeking, and relative sensitivity of losses to gains [11]. The behavior of Taiwanese freeway drivers can be analyzed using cumulative prospect theory (CPT) model feature. Loss aversion and weight function is a main part of CPT feature which utilized to investigate the potential of gains or losses [12]. In addition, in Hongkong, public transport is operated by three company operators such as bus franchise, bus nonfranchise, and railways. Of the three operators is competition each other's. Public transport policy plays a main role to increase the number of passenger. The passenger prefer to choose public transport operator that arrive earlier rather than the one with lower fare [13]. Prospect theory and mental accounting theory has been developed to modeling travel behavior choice considering internal reference point. In choosing travel mode, internal reference point plays a prominent role in choice of public transport modes [14].

In mental accounting concepts, Thaler (1999) revealed three components of mental accounting theory corresponding to the consumer choices; the evaluation of perceive and experience, the assignment of activities to specific account, and the frequency of account. The choice of the consumers are influenced by mental accounting [15]. Other research has identified that by using mental accounting theory, the perspective value of consumer online can be influenced through monetary factors (i.e., perceived price), non-monetary factors such as convenience, pleasure, and perceived risk [16]. Shifting of reference point depends on the evaluation of gains and losses. For cost and time attribute the individual is average increase in loss aversion, whereas for punctually attribute, the individual is a substantial decrease [17]. There are two ways implied to identify the reference point in invasive medical procedure: by drawing attention to future disability and by drawing attention to past disability. Reference point might be in rightside of baseline health and might be in left-side of baseline of health [18]. In security trading domain, shifting reference point can be adopted in the upward position after stock investment gains and down-ward position after losses when reference point measured in same nominal of money [19]. Dynamic reference point depends on the prediction of gains or losses. When decision maker predict gain in first session, they will reject the second session, when decision-maker predict loss in first session, they plan to take second session [20]. As far as we are aware, there are a few studies have observed the effect of the travel mode choice using prospect theory when the internal reference point is dynamic. However, the study of internal reference point using prospect theory is widely used in the marketing research field as explained in earlier.

The objective of this study is to investigate the dynamic of the internal reference point of public transport ridership after implementing transport policies. The data is analyzed using a binomial logit model approach based on mental accounting theory to find out the influences of internal reference points.

With those facts in mind, it seems that internal reference in the marketing research could also be a suitable tool to be applied in travel behavior research. This study hypothesizes the dynamic of the internal reference point is integrally mentally-related to the way of people counts for gains and losses. In this context, fare reduction, cash back and mobility management policies are utilized to investigate the dynamic of the reference point over the public transport ridership.

\section{MATERIALS AND METHODS}

\section{A. Study Area}

The research was conducted in Matsuyama City which is the capital city of Ehime Prefecture, Japan. Around 515,183 inhabitants, which consist of 240,254 men and 274,929 women distributed over an area of $429.05 \mathrm{~km}^{2}$. The population density of inhabitants $/ \mathrm{km}^{2}$ is almost 1.199 and the number of households is of 235,178 [21]. The city of Matsuyama is a small area. The distance between a residential area and central business district (CBD) is not so far. Therefore, it does not need much time to reach the destination to such area. In the city, commuter tends to use the private car rather than public transport. Therefore, it is interesting to analyze how the intention of private car user could be shifted to use public transport and to what extent transport policies can influence the public transport ridership, particularly in the short-distance trip. This city provides several transport modes such as bus line (Orange line, Iyotetsu, Japan Railways), taxi, and bicycle.

\section{B. Data Collection and Analysis}

The travelers were chosen as the primary sampling unit. A structured questionnaire was administrated to the randomly selected of 148 respondents. Those who are agreed to participate were interviewed. This study emphases on shortdistance trip, for example, traveling from resident area as origin to central business districts as destination such as Gintengai, Okaido, and Takashimaya. Stated preference (SP) is widely used in travel behavior research and practice to identify behavioral responses for choosing the situation. In this case, the SP is not revealed by the modified existing choices. However, the revealed preference model is also introduced in SP for predicting response due to anticipating question [22]. Some aspects that covered in the questionnaire are as follows;

- Socio-economic and demographic characteristics, including: gender, age category, driver license, car ownership, and zip code.

- Transport user characteristics, including: the most frequent mode of transport used such as private car or public transport per week, the most frequent purpose of transport user goes to CBD, stated preference questions corresponding reference points such as perceived cost, 
reservation cost, fair cost and actual cost, as well as travel time.

- Experimental scenarios: the questionnaire consists of fifty-two questions. It is divided into three scenarios of pre-post transport policy implementation: fare reduction, cash-back, and mobility management.

Stated preference is utilized in order to describe the hypothetical scenarios.

TABLE I

HYPOTHETICAL SCENARIOS

\begin{tabular}{|c|c|c|c|c|}
\hline \multirow{2}{*}{$\begin{array}{c}\text { Disc } \\
\text { pattern }\end{array}$} & $\begin{array}{l}\text { disc } \\
\text { rate }\end{array}$ & $\begin{array}{c}\text { cost pay } \\
\text { (JPY) }\end{array}$ & $\begin{array}{c}\text { cashback } \\
\text { (JPY) }\end{array}$ & cost rate \\
\hline & 1 & 2 & $3=(1 / 2)$ & $4=(3 / 2)$ \\
\hline 1 & $10 \%$ & 2000 & 200 & 0.1 \\
\hline 2 & $10 \%$ & 5000 & 500 & 0.1 \\
\hline 3 & $20 \%$ & 2000 & 400 & 0.2 \\
\hline 4 & $20 \%$ & 5000 & 1000 & 0.2 \\
\hline 5 & $50 \%$ & 2000 & 1000 & 0.5 \\
\hline 6 & $50 \%$ & 5000 & 2500 & 0.5 \\
\hline
\end{tabular}

Table 1 shows the hypothetical scenarios of public transport fare, it consists of six discount patterns. The $1^{\text {st }}$ and $2^{\text {nd }}$ discount pattern are provided to calculate $10 \%$ discount rate for $2000 \mathrm{JPY}$ and $5000 \mathrm{JPY}$ cost pay, for $3^{\text {rd }}$ and $4^{\text {th }}$ discount pattern are provided to calculate $20 \%$ discount rate for $2000 \mathrm{JPY}$ and $5000 \mathrm{JPY}$ cost pay, and for $5^{\text {th }}$ and $6^{\text {th }}$ discount pattern are provided to calculate $50 \%$ discount rate for cost pay. Discount rate and cost pay are provided to calculate the amount of cash-back and fare reduction policy. Also, to provide the respondents who asked correspondent of the reference point for public transport fare before and after applying 6 hypothetical scenarios. This research analyzes the reference points in three attributes: reference point in the travel time (TT) and travel cost (TC) for public transport, also reference point in travel time for private car. Both travel time and travel cost for public transport seek the reference point in terms of actual, perceived, fair, and reservation time and cost respectively. Whereas, travel time for private car seeks in average, maximum, and minimum travel time.

There are two scaling functions can be found in prospect theory; the value function and weight function. The value function represents a prospect (i.e., possible outcomes and it consequences) in terms of the increase and decrease in the amount of asset from a reference point and weight function represents a scale of the probability [8]. Thaler (1985) introduced four ways of joint outcome in the mental accounting and consumer's choice for consumer behavior. The joint outcome combination consist of: firstly, multiple gains (pure gains), involving two positive events; secondly, multiple losses (pure losses), involving two negative events; third, mixed gains, involving a large gain and a small loss; fourth, mixed loss, involving a small gain and a large loss [23].

Transport policy has continuing been developed in the last few decades concerning how to increase public transport usage instead of the private car. This study analyzes the impact of transport policies on the public transport ridership, particularly, the impact of transport policies before and after implementing transport policy which the internal reference point refers to mental accounting theory. The dynamic of the internal reference point (IRP) can be shown in Fig. 1.

The initial evaluation of the reference point before implementation of transport policy (RP1) is designed for a current position of fair cost. The second evaluation of the reference point after implementation of transport policies (RP2) is also made against a current position of fair cost. A different position corresponding to gain and losses over the RP1 and RP2 is made as a final decision. This description suggests that the dynamic of the reference point depends on the utility value of gains and losses.

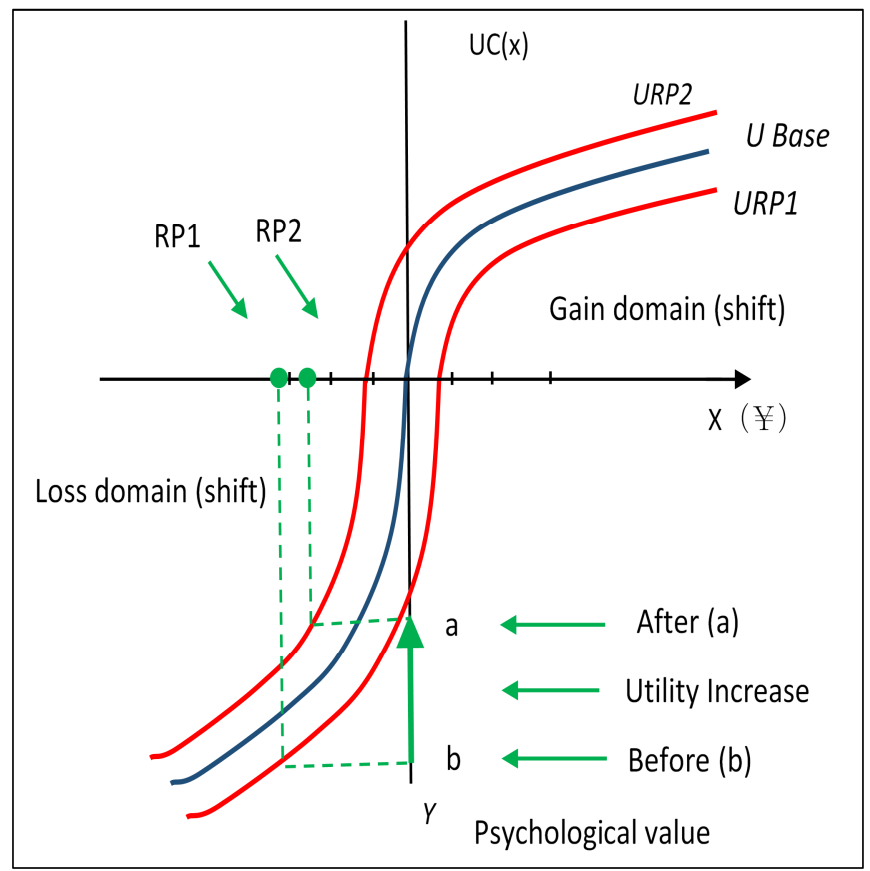

Fig. 1 Dynamic IRP after implementing transport policy

A detail of a specific implementing transport policies is shown in Fig. 1. $X$ axis defined as transport fare (JPY) and $U_{\text {Base }}(X)$ as utility function used to investigate the reference point before and after implementing transport policies. $U_{R P 1}(X)$ defined as utility function used to investigate the reference point before implementing transport policies. $U_{R P 2}(X)$ defined as utility function used to investigate the reference points after implementing transport policies. Reference points refer to the $X$ axis value which is assigned zero utility by the utility function, it can be in gain or loss area. There are three transport policies will be analyzed as follows.

1) Fare Reduction (FR) Policy: One of the transport policies is fare reduction. In fare reduction policy, travelers are assumed that they receive fare reduction directly when make a payment for buying a ticket. This transport policy is expected to influence the intention of travelers to use public transport. The dynamic of the reference point after implementing FR, and its impact on the utility value of gains and losses depicted in Fig. 1. RP1 and RP2 define the reference points before and after implementing FR over utility base $U_{\text {Base }}(X)$. A shift in the losses area reflects a left-side shift of reference point from utility base $U_{B \text { ase }}(X)$ to RP1. And a shift in gains area reflect a right-side shift of a reference point from utility base $U_{B a s e}(X)$ to RP2. Ridership 
evaluation to gains and losses depends on a current reference point of which utility value is considered. Fig. 2 describes the relationship between the dynamic reference point and the discount rate for fare reduction policy.

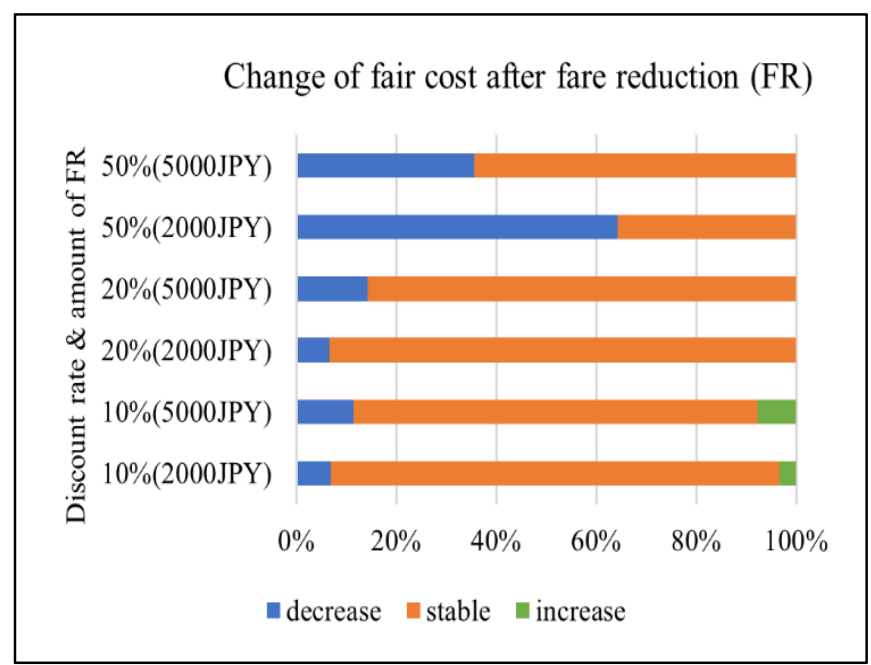

Fig. 2 Fare reduction policy

As shown in Fig. 2, after implementing fare reduction policy, the change of reference point in the decrease position for the discount rate $10 \%$ of $2000 \mathrm{JPY}$ and $10 \%$ of 5000 JPY are $6.9 \%$ and $11.5 \%$ simultaneously. Furthermore, for the discount rate $20 \%$ of 2000 JPY and $20 \%$ of 5000 JPY change of reference point is $6.7 \%$ and $14.3 \%$ respectively. Whereas for the discount rate $50 \%$ of $2000 \mathrm{JPY}$ and $50 \%$ of 5000 JPY the value of the change in reference point become $64.3 \%$ and $35.7 \%$ correspondingly. On the other hand, in the stable position for the discount rate $10 \%$ of 2000 JPY and $10 \%$ of $5000 \mathrm{JPY}$ the change of reference point is 89.6 and $80.8 \%$ in order. For the discount rate $20 \%$ of 2000 JPY and $20 \%$ of $5000 \mathrm{JPY}$ is $93.3 \%$ and $85.7 \%$ change of reference respectively. In addition, for discount rate $50 \%$ of $2000 \mathrm{JPY}$ and $50 \%$ of $5000 \mathrm{JPY}$ change of reference point is $35.7 \%$ and $64.3 \%$ subsequently. In the increase position, the discount rate $10 \%$ of 2000 JPY and $10 \%$ of 5000 JPY there are $3.5 \%$ and $7.7 \%$ change of reference point simultaneously. There is no change of reference point for both the discount rate $20 \%$ and $50 \%$. It can be said that the reference point of public transport ridership mostly stable and significantly decrease as a discount rate increased.

\section{2) Cash-back Policy}

Cash-back policy is also utilized to observe the dynamic of internal reference point. In cash-back policy, the amount of payment is stable, but the amount of cash-back might be evaluated by gain frame. In this context, payment by cashback policy, public transport ridership feels that they are in losses area due to payment by cash-back must be paid earlier. However, they will get gains in total payment by cash back. Cash-back policy might be a little bit different with fare reduction in terms of evaluating the utility of gain and loss. In cash-back policy, passengers do not receive fare reduction directly at the time ticket is paid, however they will receive the money back in the certain time, whereas fare reduction policy, passengers get fare reduction directly at the time the ticket is paid. By this phenomenon, we acquire some theoretical predictions regarding cash-back policy refers to the silver lining effect. The relationship between the dynamic reference point and the discount pattern of cashback policy in Fig 3.

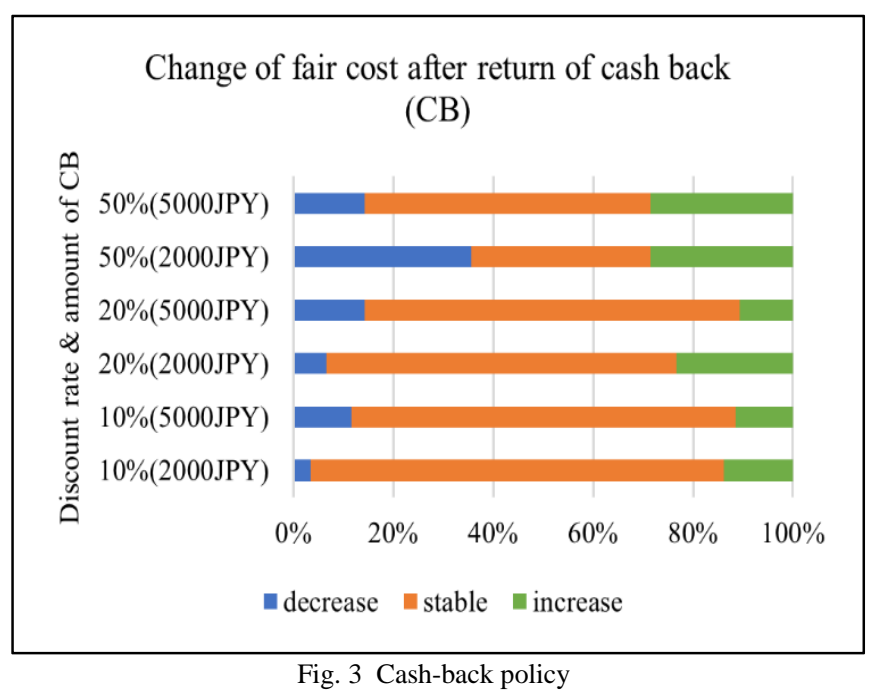

Fig. 3 describes the reference point of public transport ridership differs in any level of the discount pattern after implementing cash-back policy. It can be seen that in the decrease position the discount rate $10 \%$ of 2000 JPY and $10 \%$ of $5000 \mathrm{JPY}$ resulted in $3.4 \%$ and $11.5 \%$ change of reference point. For the discount rate $20 \%$ of 2000 JPY and $20 \%$ of $5000 \mathrm{JPY}$ the change of reference point is $6.7 \%$ and $14.3 \%$ respectively. In addition, for the discount rate $50 \%$ of 2000 JPY and $50 \%$ of 5000 JPY change of reference point is $35.7 \%$ and $14.3 \%$ subsequently. Additionally, in the stable position the discount rate $10 \%$ of 2000 JPY and $10 \%$ of 5000 JPY gives each $82.8 \%$ and $76.9 \%$ change of reference point. For the discount rate $20 \%$ of 2000 JPY and $20 \%$ of 5000 JPY change of reference point is $70 \%$ and $75 \%$ in order. Moreover, for the discount rate $50 \%$ of 2000 JPY and $50 \%$ of 5000 JPY change of reference point is $35.7 \%$ and $57.1 \%$ correspondingly. In the increase position, for the discount rate $10 \%$ of 2000 JPY and $10 \%$ of 5000 JPY change of reference point is $13.8 \%$ and $11.5 \%$ respectively. For the discount rate $20 \%$ of 2000 JPY and $20 \%$ of 5000 JPY is $23.3 \%$ and $10.7 \%$ change of reference point in order. Furthermore, the discount rate $50 \%$ of 2000 and $50 \%$ of 5000 JPY gives the value of $28.6 \%$ and $28.6 \%$ in a change of reference point.

The decrease reference point is lined up as the discount rate increased, but it is not significant. Whereas, the increase reference point is increased significantly as monetary amounts of cash-back increased.

\section{3) Mobility Management}

The mobility management policy is also utilized to evaluate the dynamic reference point. In this research, mobility management focused only on $\mathrm{CO} 2$ emission from public transport and private car. The information about $\mathrm{CO} 2$ emission toward travelers is expected to increase the awareness regarding the emission and assisted to them make a travel decision. Shifting of reference points depends on the utility value of gains and losses. If public transport ridership 
feels that they obtain gains from this policy, so that they will maintain its position in gains domain, however if they feel that the policy would give less benefit, then they would not consider for shifting to use public transport. Travelers perceived that there is no direct advantage from this policy due to long period of benefit acquisition from mobility management policy. Therefore, the movement of the reference point is less significant.

A finding on travel choice correspondent to $\mathrm{CO} 2$ emission suggests that transport user who less information about $\mathrm{CO} 2$ emission, they do not consider the effect of $\mathrm{CO} 2$ emission [24]. Also, people who are less informed on $\mathrm{CO} 2$ will affect their interpretation of how sustainable something is. On another study observed that there is effects $\mathrm{CO} 2$ amount toward perceived differences and loss framing of $\mathrm{CO} 2$ emission information influences transport choices [25]. This study is based on the frame that in Japan, transportation sector contributes to $20 \%$ of $\mathrm{CO} 2$ emission and approximately $55 \%$ out of the $20 \%$ is from the private car contribution. Description of $\mathrm{CO} 2$ emission that would lead to climate change and therefore should be avoided was not considered. The relationship between dynamic reference point and value of $\mathrm{CO} 2$ emission as described in Fig. 4.

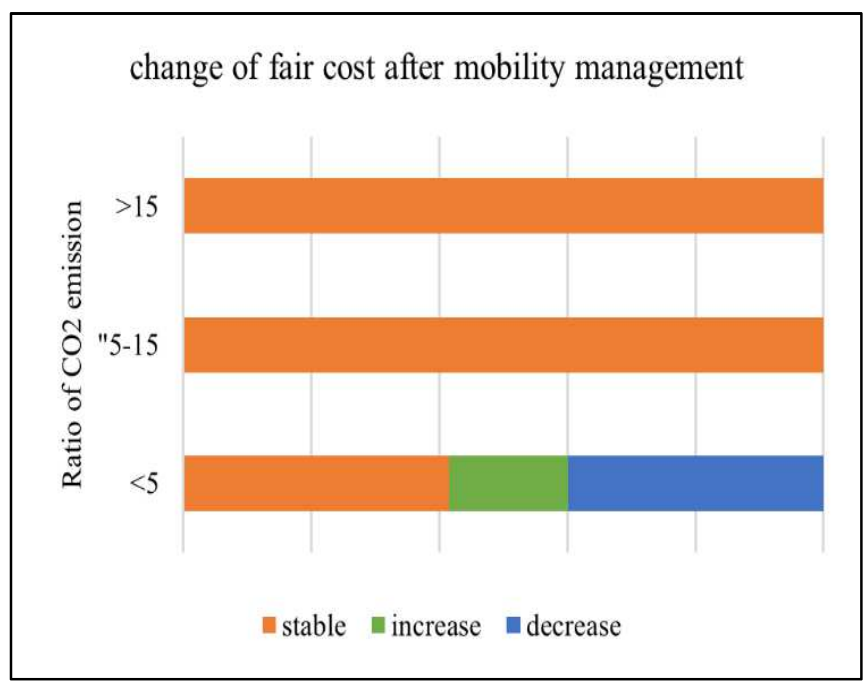

Fig. 4 Mobility management policy

We assume that $\mathrm{CO} 2$ ratio valued from $5-15$ means the quite ratio of public transport ridership, the value less than 5 or more than 15 which means that the underestimate and overestimate value of the ratio respectively. Fig. 4 shows that ratio emission tends to stable at the value of more than 15 and among 5-15, slightly increase and tends to decrease at the value of less than 5. It might be concluded that in this policy reference point tends to be stable.

\section{RESULTS AND DISCUSSION}

Collecting data using the stated preference (SP) questionnaire survey was used. Parameters were determined by employing binary logit model formulation. We divided three-part sub-sections to describe the main result.

\section{A. Results}

\section{1) Setting of Reference Point}

The reference point is a zero-asset position from which the deviation measured each prospect as a gain or loss [8]. Public transport ridership conscious of the convenience of public transport system, planning a journey trip, transport mode or schedule of public transport in order to take decision making. Public transport ridership perceived a reference point might represent a threshold value that the differences between gains and losses in the context of travel behavior modeling. By using binomial logit model, we analyze attribute such as travel time and travel cost for public transport, and travel time for private car. By the three attributes, hereafter, it was then determined fair travel cost of public transport as reference point due to McFadden pseudo value $\rho^{-2}$ is closer to 1 and AIC an Akaike's Information Criteria is smallest. The value of AIC and $\rho^{-2}$ are 283,53 and 0,21 respectively. For a binary choice model, the value of goodness-of-fit McFadden pseudo $\rho^{-2}$ is in range of 0 to 1 . The value closer to 1 is considered as much better [26].

\section{2) The Dynamic of Reference Point for Fare Reduction Policy}

The reference point in the travel cost for public transport was estimated after implementing fare reduction. It found that there were 113 travelers in a stable position, 25 travelers were in the decrease position, and 3 travelers were in the increase position. The reference point (RP) increased if the value of RP after implementing fare reduction went up, and it decreases if the value of RP went down. However, the value was stable if RP before and after implementation is equal. Also, it was found that the mean of RP in before and after implementing fare reduction is 204,25 and 192,19 respectively. It showed that in individual-level, reference point after implementing fare reduction tends to decrease. Travelers tend to behave differently when information is framed in terms of gains and loss. In prospect theory, the value function curvature of gains and losses are assumed to be concave and convex respectively. It is consistent with the data that have been analyzed. The estimation results of fare reduction, cash-back and mobility management describes in Table 2.

In previous analysis found that the reference points (RP) after implementing fare reduction tends to increase. It means that if reference points decrease, gains area will increase, and losses area will decrease, hence the value of utility function would be automatically increased. If the reference points of the travelers increase, it means the gains area will decrease and losses area will increase. It is consistent with mental accounting theory. Table 2 shows estimation result of fare reduction, cash-back, and mobility management policy. It seems that the variables of fare reduction policy such as the frequency of public transport and ratio of fare reduction would give more significant in implementing this policy.

\section{3) The Dynamic of Reference Point for Cash-back Policy}

The reference point of fair travel cost for public transport after implementing cash-back policy showed as an individual level that 99 travelers were in the stable position, 25 travelers were in the increase position, and 17 travelers were in the decrease position. Additionally, the mean of the reference point before and after implementing cash-back is 2014,25 and 206,59 respectively. With those fact in mind, it 
could be interpreted that the reference point tends to increase after implementing cash-back policy. It could also be concluded that the reference points of public transport ridership are dynamic. It depends on the gains and losses domain. As shown in Table 2 the most significant variable of cash-back policy is gender particularly male, the frequency of public transport and the amount of cash-back.

TABLE II

ESTIMATION RESULT

\begin{tabular}{|c|c|c|c|c|c|c|}
\hline \multirow{3}{*}{ Variables } & \multicolumn{6}{|c|}{ Estimation Result } \\
\hline & \multicolumn{2}{|c|}{ Fare Reduction } & \multicolumn{2}{|c|}{ Cash-back } & \multicolumn{2}{|c|}{ Mobility Management } \\
\hline & Estimates & t-statistic & Estimates & t-statistic & Estimates & t-statistic \\
\hline$\theta_{1}$ & -1.56 & -2.89 & -1.00 & -1.79 & -0.87 & -2.08 \\
\hline$\theta_{2}$ & 1.74 & 3.08 & 1.35 & 2.40 & 1.44 & 3.34 \\
\hline male & & & 1.13 & 2.76 & & \\
\hline Age 30 & & & & & 0.69 & 2.03 \\
\hline Frequency of PT & -0.12 & -1.96 & -0.11 & -2.16 & -0.11 & -2.10 \\
\hline Amount of CB & & & -0.24 & -2.33 & & \\
\hline Rate FR & -3.69 & -3.76 & & & & \\
\hline $\mathrm{CO} 2$ Answer & & & & & 0.04 & -0.37 \\
\hline $\mathrm{N}$ observations & \multicolumn{2}{|c|}{113.00} & \multicolumn{2}{|c|}{113.00} & \multicolumn{2}{|c|}{113.00} \\
\hline
\end{tabular}

\section{4) The Dynamic of Reference Point for Mobility Management Policy}

Based on the estimation results, it found 75 travelers were in the stable position, 21 travelers were in the increase position, and 45 travelers were in the decrease position. In addition, the mean of the reference point before and after implementing mobility management is 204,25 and 210,64 respectively. Hence the reference points of fair travel cost are more likely to stable before and after implementing mobility management policy. Table 2 revealed that the estimation results of variables for mobility management showed the frequency of public transport and male (30 years old) are more significant in this policy.

\section{B. Discussion}

This research describes the dynamic of internal reference point for public transport ridership after implementing transport policies. The reference point of public transport ridership after implementing of fare reduction policy tends to stable and significantly decrease as a discount rate increase, and the reference point of public transport ridership after implementing of cash-back policy tends to increase significantly as monetary amount of cash-back increased. Those results could be said that the reference point of public transport ridership after implementing transport fare policy is dynamic. These results are in line with previous studies [17] [20], respondents are likely to take significant reaction when they are in a negative reference point position. When respondent did not get gain in the first choice, they consider taking the second choice. Whereas they changed their intention and disagreed the choice, after experiencing gain. If someone obtained the gain in the first gambling, they would accept a second identical gambing. However, when they imagine the output of the first gambling was unknown, they would reject the second gambling. The reference points of the public transport ridership after implementing mobility management policy tends to a stable position. The public transport ridership likely to disregard the effect of $\mathrm{CO} 2$ emission in using public transport. In addition, the phenomenon of the effect of $\mathrm{CO} 2$ emission such as loss framing of $\mathrm{CO} 2$ amounts, $\mathrm{CO} 2$ emission information have also been studied in the transport field in earlier studies [24][25]. CO2 information should be introduced to public transport user to affect transport choice. This study also refers to the mental accounting and consumer choice [5], particularly combination outcomes by mixed loss model. Hence, the recent study, it showed that after implementing fare transport policies and mobility management policy, public transport ridership tends to be utility maximizer and to be more interested in a small gain rather than big loss (mixed loss).

\section{IV.CONCLUSION}

This study investigated the dynamic of reference points of the public transport ridership after implementing transport policies based on the mental accounting theory. The transport policies such as fare reduction, cash back, and mobility management are utilized to analyze the dynamic of reference points. By this research can be drawn a conclusion that the travelers are more likely to change reference point when they realize losses than gains. Similarly, the way of public transport ridership combines the decrease and increase of the utility value showed that travelers would like to select which gains and losses occur simultaneously, so that the integration outcome is more desirable than segregation outcomes. In this study, it was introduced a psychological decision-making model which refers to the mental accounting theory and found that it plays a prominent role in order to influence the decision of public transport ridership. Also shows that in cash-back policy the reference point tends to increase as a discount rate increase, it means the utility will increase. Therefore, cash-back policy seems 
to be more effective to promote the public transport usage. Given the importance change of the reference point, the development of mental accounting theory and prospect theory in transport field and modeling travel behavior, particularly on framing segregation or integration could have an influence on the public transport ridership still need to be explored further.

\section{ACKNOWLEDGMENT}

This research is supported by DIKTI Scholarship Batch 4, 2014.

\section{REFERENCES}

[1] Avineri E. On the use and potential of behavioural economics from the perspective of transport and climate change. J Transp Geogr [Internet]. Elsevier Ltd; 2012;24:512-21. Available from: http://dx.doi.org/10.1016/j.jtrangeo.2012.03.003

[2] Ismail A, Elmloshi AE. Logistic Regression Models to Forecast Travelling Behaviour in Tripoli City. Int J Adv Sci Eng Inf Technol [Internet]. INSIGHT, Indonesian Society for Knowledge and Human Development; 2011 [cited 2017 Jul 28];1(6):618-23. Available from: http://ijaseit.insightsociety.org/index.php?option=com_content\&view $=$ article \&id $=9 \&$ Itemid $=1 \&$ article_id $=124$

[3] Mansyur R, Rahmat RAOK, Ismail A, Kabit MR. Knowledge based expert advisory system for transport demand management. Proceeding Int Conf Adv Sci Eng Inf Technol [Internet]. 2011;652-7. Available from: http://ijaseit.insightsociety.org/index.php?option=com_content\&view $=$ article\&id $=9 \&$ Itemid $=1 \&$ article_id $=130$

[4] Kahneman D, Tversky A. Prospect theory: An analysis of decision under risk. Econom J Econom Soc [Internet]. The Econometric Society; 1979;47(2):263-92. Available from: http://www.jstor.org/stable/1914185

[5] Thaler R. Mental Accounting and Consumer Choice. Mark Sci [Internet]. 1985;4(3):199-214. Available from: http://www.jstor.org/stable/183904

[6] Van De Kaa EJ. Prospect Theory and Choice Behaviour Strategies: Review and Synthesis of Concepts from Social and Transport Sciences. Eur J Transp Infrastruct Res [Internet]. 2010;10(4):299329. Available from: www.ejtir.tbm.tudelft.nl

[7] Van De Kaa EJ. Extended Prospect Theory: Findings on choice behaviour from economics and the behavioural sciences and their relevance for travel behaviour [Internet]. Delf University; 2008. Available from: https://repository.tudelft.nl/islandora/object/ uuid:59ddafbf-48ad-4d0f-b0b3-cec5f1010099?collection=research

[8] Senbil M, Kitamura R. Reference Points in Commuter Departure Time Choice: A Prospect Theoretic Test of Alternative Decision Fames. J Intell Transp Syst [Internet]. 2004;8(1):19-31. Available from: http://www.tandfonline.com/page/terms-and-conditions

[9] Avineri E. A Cumulative Prospect Theory Approach to Passengers Approach to Passengers Behavior Modeling : Waiting Time Paradox. Intell Transp Syst [Internet]. 2004;8(4):195-204. Available from: http://www.tandfonline.com/page/terms-and-conditions

[10] Avineri E, Bovi PHL. Identification of Parameters for Prospect Theory Model for Travel Choice. Transp Res Rec [Internet]. 2008;(2082):141-7. Available from: http://dx.doi.org/10.3141/208217

[11] Xu H, Zhou J, Xu W. A decision-making rule for modeling travelers route choice behavior based on cumulative prospect theory. Transp Res Part C [Internet]. Elsevier Ltd; 2011;19(2):218-28. Available from: http://dx.doi.org/10.1016/j.trc.2010.05.009

[12] Jou R-C, Chen K-H. An application of cumulative prospect theory to freeway drivers' route choice behaviours. Transp Res Part A Policy Pract [Internet]. 2013;49:123-31. Available from: http://dx.doi.org/10.1016/j.tra.2013.01.011
[13] Tang S, Lo HK. The impact of public transport policy on the viability and sustainability of mass railway transit - The Hong Kong experience. Transp Res Part A Policy Pract [Internet]. 2008;42(4):563-76. Available from: http://www.sciencedirect.com/ science/article/pii/S0965856408000025

[14] Sarif, Kurauchi S, Yoshii T. Development of discrete choice model considering internal reference points and their effects in travel mode choice context. IOP Conf Ser Earth Environ Sci [Internet]. IOP Publishing; 2017 Jun [cited 2017 Jun 26];71(1):12020. Available from: $\quad$ http://stacks.iop.org/1755-1315/71/i=1/a=012020? key $=$ crossref.f35ce12ecbb8fdc45dd5df89ed221195

[15] Thaler RH. Mental accounting matters. J Behav Decis Mak [Internet]. 1999;12(3):183-206. Available from: https://5aeed477-a-62cb3a1as-sites.googlegroups.com/site/xiaoliangtushuguanfenguan3/gm937 xing-xiao-zhuan-ti-yan-

tao/Thaler1999.pdf?attachauth=ANoY7cp8KXph_2aOHePmk0-

DqLwflu3L30GT60dTUwadjrDZwi_OUtasUwHWuSPTLG9gcSG2 0WRBWC5cQnkgJafBz9G-PsVPe8WfoYJbCWI0hqtj

[16] Gupta S, Kim H-W. Value-driven INTERNET shopping: The mental accounting theory perspective Value-Driven Internet Shopping: The Mental Accounting Theory. Psychol Maket [Internet]. 2010;27(1):13-35. Available from: htpp:www.research.net/publication/229878930

[17] Masiero L, Hensher DA. Shift of reference point and implications on behavioral reaction to gains and losses. Transportation (Amst) [Internet]. 2011;38(2):249-71. Available from: https://link.springer.com/article/10.1007/s11116-010-9302-0

[18] Schwartz A, Goldberg J, Hazen G. Prospect theory, reference points , and health decisions. Judgm Decis Mak [Internet]. 2008;3(2):174-80. Available https://link.springer.com/article/10.1007/BF02894508

[19] Arkes HR, Hirshleifer D, Jiang D, Lim S. Reference point adaptation : Tests in the domain of security trading. Organ Behav Hum Decis Process [Internet]. 2008;105(1):67-81. Available from: http://www.sciencedirect.com/science/article/pii/S074959780700043 $\mathrm{X}$

[20] Barkan R, Busemeyer JR. Modeling Dynamic Inconsistency with a Changing Reference Point. J Behav Decis Mak [Internet]. 2003;16(4):235-55. Available from: http://onlinelibrary.wiley.com/doi/10.1002/bdm.444/full

[21]人口松山市ホームページ [Internet]. [cited 2017 Feb 9]. Available from: https://www.city.matsuyama.ehime.jp/shisei/tokei/toukei2.html

[22] Hensher DA. Stated preference analysis of travel choices: the state of practice. Transportation (Amst) [Internet]. 1994;21(2):107-33. Available from: https://link.springer.com/article/10.1007\%2FBF01098788?LI=true

[23] Linville PW, Fischer GW. Preferences for separating or combining events. J Pers Soc Psychol [Internet]. 1991;60(1):5-23. Available from: http://psycnet.apa.org/record/1991-15253-001

[24] Waygood EO, Avineri E. Does " $500 \mathrm{~g}$ of CO2 for a five mile trip" mean anything? Towards more effective presentation of information. Proceedings of the Transportation Research Board 90th Annual Meeting, Washington DC,USA [Internet]. 2011. p. 23-7. Available from: http://carbonaware.devisu.be/fileadmin/user_upload/Publications/O W_and_EA_Information_coding_and the_editing_phase_4.pdf

[25] Waygood O, Avineri E (2011b). The Effect of Loss Framing On The Perceived Difference of CO2 Amounts' Implications for Advanced Travel Information Systems (ATIS). The 43rd Annual USTG (The Universities' Transport Study group) Conference, Milton Keynes [Internet]. United Kingdom: UTSG; 2011. Available from: http://eprints.uwe.ac.uk/16918/

[26] Ben-Akiva M, Lerman SR. Discrete Choice Analysis: Theory and Application to Travel Demand. Amerika: MIT Press; 1985. 